\title{
Assessment of the potential vaping-related exposure to carbonyls and epoxides using stable isotope-labeled precursors in the e-liquid
}

\author{
Anne Landmesser ${ }^{1,3} \cdot$ Max Scherer $^{1} \cdot$ Gerhard Scherer $^{1} \cdot$ Mohamadi Sarkar $^{2} \cdot$ Jeffery S. Edmiston $^{2}$. \\ Reinhard Niessner $^{3} \cdot$ Nikola Pluym $^{1}$ (1)
}

Received: 12 April 2021 / Accepted: 15 June 2021 / Published online: 22 June 2021

(c) The Author(s) 2021

\begin{abstract}
The formation of carbonyls and epoxides in e-cigarette (EC) aerosol is possible due to heating of the liquid constituents. However, high background levels of these compounds have inhibited a clear assessment of exposure during use of ECs. An EC containing an e-liquid replaced with $10 \%$ of ${ }^{13} \mathrm{C}$-labeled propylene glycol and glycerol was used in a controlled use clinical study with $20 \mathrm{EC}$ users. In addition, five smokers smoked cigarettes spiked with the described e-liquid. Seven carbonyls (formaldehyde, acetaldehyde, acrolein, acetone, crotonaldehyde, methacrolein, propionaldehyde) were measured in the aerosol and the mainstream smoke. Corresponding biomarkers of exposure were determined in the user's urine samples. ${ }^{13} \mathrm{C}$-labeled formaldehyde, acetaldehyde and acrolein were found in EC aerosol, while all seven labeled carbonyls were detected in smoke. The labeled biomarkers of exposure to formaldehyde $\left({ }^{13} \mathrm{C}\right.$-thiazolidine carboxylic acid and ${ }^{13} \mathrm{C}-\mathrm{N}$-(1,3-thiazolidine4-carbonyl)glycine), acrolein $\left({ }^{13} \mathrm{C}_{3}\right.$-3-hydroxypropylmercapturic acid) and glycidol $\left({ }^{13} \mathrm{C}_{3}\right.$-dihydroxypropylmercapturic acid) were present in the urine of vapers indicating an EC use-specific exposure to these toxicants. However, other sources than vaping contribute to a much higher extent by several orders of magnitude to the overall exposure of these toxicants. Comparing data for the native (unlabeled) and the labeled (exposure-specific) biomarkers revealed vaping as a minor source of user's exposure to these toxicants while other carbonyls and epoxides were not detectable in the EC aerosol.
\end{abstract}

Keywords Electronic cigarettes · Biomarkers of exposure - Carbonyls · Epoxides · Stable isotope-labeled constituents · Mercapturic acids

\section{Introduction}

The use of e-cigarettes (ECs) has increased over the past several years (Beard et al. 2020; Cullen et al. 2019; Dai and Leventhal 2019; Kapan et al. 2020). As use of ECs become more prevalent, it becomes more important to understand the potential exposure to harmful chemicals during use of these products. One area of focus is the potential formation of carbonyls, epoxides, and aromatic amines by thermal degradation of e-liquid constituents, despite the much lower

Nikola Pluym

nikola.pluym@abf-lab.com

1 ABF Analytisch-Biologisches Forschungslabor GmbH, Semmelweisstrasse 5, 82152 Planegg, Germany

2 Altria Client Services LLC, Center for Research and Technology, Richmond, VA, USA

3 Chair for Analytical Chemistry, Technische Universität München, Marchioninistraße, Munich, Germany temperatures during vaping $\left(<350{ }^{\circ} \mathrm{C}\right)$ compared to conventional smoking (up to $900{ }^{\circ} \mathrm{C}$ ) (Farsalinos et al. 2015b; Gillman et al. 2016; Hutzler et al. 2014; Tayyarah and Long 2014) and the resulting exposure to those toxicants by EC vaping.

The major constituents of e-liquids are propylene glycol (PG), glycerol (G), nicotine, water and flavors. The aerosol is formed by heating the e-liquid and during this process PG and G may be decomposed into toxicants such as the carbonyls formaldehyde (FA), acetaldehyde (AA), acrolein (ACR), and crotonaldehyde (CR) as well as the epoxides glycidol (GLY) or propylene oxide (PO), to which vapers might be exposed (Fig. 1) (Flora et al. 2016; Sleiman et al. 2016; Sodhi and Khanna 2015; Uchiyama et al. 2020).

The aforementioned carbonyls and epoxides are found in the environment, in food, as well as possibly formed endogenously (Bakhiya et al. 2011; Feron et al. 1991; Moghe et al. 2015). Hence, identifying the EC-specific contribution to carbonyl and epoxide exposure is challenging. In the case of 


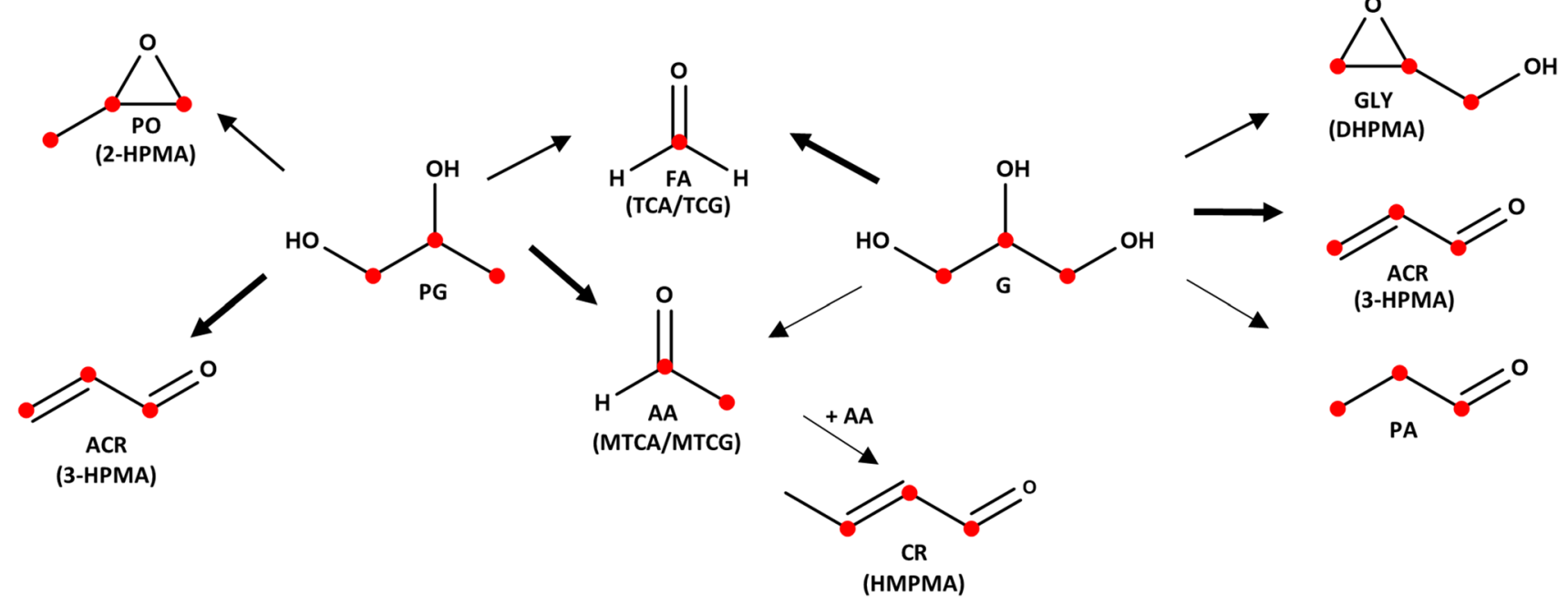

Fig. 1 Overview of the thermal degradation products formed from propylene glycol (PG) and glycerol (G). The stable isotope-labeled ${ }^{13} \mathrm{C}$-atoms are illustrated as red dots in the structures. The thickness of the arrows represent the contribution of PG and G to the formation of the degradation products formaldehyde (FA), acetaldehyde (AA), acrolein (ACR), propionaldehyde (PA), crotonaldehyde (CR), glycidol (GLY), and propylene oxide (PO) according to Sleiman et al.

ECs, this problem can be circumvented using stable isotopelabeled PG and G in the e-liquid. Studies using stable isotope tracers have long been used in mass spectrometry as the "gold" standard method for understanding kinetics, uptake, distribution, metabolism and elimination of various compounds in living organisms (Bequette et al. 2006; Darmaun and Mauras 2005; Evershed et al. 2006; Wittmann 2002).

Our approach comprised of the analysis of carbonyls and epoxides in the aerosol derived from ECs containing e-liquids in which $10 \%$ of $\mathrm{PG}, \mathrm{G}$ and nicotine were replaced by stable isotope-labeled analogues, as well as the determination of corresponding biomarkers in the urine of vapers who used these ECs in a clinical study under controlled but realistic vaping conditions. We hypothesized that the compounds which were predominantly formed by degradation of PG and G should be present at a ratio of approx. 10:1 between the native (unlabeled) and the labeled form in the aerosol. Higher ratios would indicate other sources than PG and $\mathrm{G}$ for their formation during aerosol generation. This ratio can give an estimation with respect to product usespecific uptake by measuring the corresponding biomarkers of exposure in urine, namely thiazolidine carboxylic acid (TCA) and $N$-(1,3-thiazolidine-4-carbonyl)glycine (TCG) for FA, methyl-thiazolidine carboxylic acid (MTCA) and $N$-(2-methyl-1,3-thiazolidine-4-carbonyl)glycine (MTCG) for AA, 2,3-dihydroxypropylmercapturic acid (DHPMA) for GLY, 3-hydroxypropylmercapturic acid (3-HPMA) for ACR, 3-hydroxy-1-methylpropylmercapturic acid (HMPMA) for CR, and 2-hydroxypropylmercapturic acid (2-HPMA)
(2016) Uchiyama et al. (2020) and our own findings. The corresponding biomarkers ((methyl-)thiazolidine carboxylic acid ((M)TCA), (methyl-)thiazolidine carbonyl glycine ((M)TCG), 2,3-dihydroxypropylmercapturic acid (DHPMA), 3-hydroxypropylmercapturic acid (3-HPMA), 2-hydroxypropylmercapturic acid (2-HPMA), hydroxymethylpropylmercapturic acid (HMPMA) are shown in brackets

for PO (Fig. 2). Smokers using cigarettes spiked with the labeled PG, G and nicotine were also included as "positive control' in the clinical study. It was assumed that at the high temperature of tobacco combustion the labeled carbonyls and epoxides are formed and can be detected in mainstream smoke (Diekmann et al. 2006; Sampson et al. 2014) as well as the corresponding labeled biomarkers in the smokers' urine.

\section{Materials and methods}

\section{Clinical Study}

The clinical study has been described in detail earlier (Landmesser et al. 2019). Briefly, 25 healthy adult males belonging to three groups participated in the study: 5 regular smokers (smoking non-filter cigarettes spiked with $13.4 \mathrm{mg}$ ${ }^{13} \mathrm{C}_{3}$-PG, $13.6 \mathrm{mg}{ }^{13} \mathrm{C}_{3}$-G, and $2.4 \mathrm{mg} \mathrm{D}$-nicotine dissolved in $100 \mu \mathrm{L}$ ethanol per cigarette), 10 regular vapers (vapinglabeled e-liquid at $10 \mathrm{~W}$ ) and 10 regular vapers (vapinglabeled e-liquid at $18 \mathrm{~W}$ ). In the applied e-liquid containing PG and $\mathrm{G} 50 / 50 \%(\mathrm{~m} / \mathrm{m})$ and $1.2 \%$ nicotine $(\mathrm{m} / \mathrm{m}), 10 \%$ of each PG, $\mathrm{G}$ and nicotine was replaced by ${ }^{13} \mathrm{C}_{3}-\mathrm{PG},{ }^{13} \mathrm{C}_{3}-\mathrm{G}$ and $\mathrm{D}_{7}$-nicotine, respectively. The e-liquid was tested with respect to the presence of the (un)labeled carbonyls formaldehyde, acetaldehyde, acrolein, acetone, crotonaldehyde, methacrolein, and propionaldehyde. No carbonyls were detectable in the e-liquid. The labeled compounds were 
Fig. 2 Structures of the measured metabolites. The stable isotope-labeled ${ }^{13} \mathrm{C}$-atoms are illustrated as red dots in the structures. The names of the compounds are listed in Fig. 1<smiles>[R]SCC(NC(C)=O)C(=O)O</smiles><smiles>CC(C)CCCO</smiles>

3-HPMA<smiles>CCOC(C)O</smiles>
2-HPMA<smiles>CC(C)CC(O)CO</smiles>
DHPMA<smiles>COCCC(C)C</smiles>

HMPMA<smiles>[R]C(=O)C1CSC([R])N1</smiles>

$$
\begin{aligned}
& \mathrm{R}_{1}=\mathrm{H} ; \mathrm{R}_{2}=\mathrm{OH}: \text { TCA } \\
& \mathrm{R}_{1}=\mathrm{H} ; \mathrm{R}_{2}=\mathrm{NHCH} \mathrm{COOH}: \text { TCG } \mathrm{R}_{1}=\mathrm{CH}_{3} ; \mathrm{R}_{2}=\mathrm{OH}: \text { MTCA } \\
& \mathrm{R}_{1}=\mathrm{CH}_{3} ; \mathrm{R}_{2}=\mathrm{NHCH} \mathrm{HOOH}_{2} \text { MTCG }
\end{aligned}
$$

purchased from AptoChem, Montreal, Canada. All three substances were characterized for their identity, chromatographic purity, water content, and residual solvents. ${ }^{13} \mathrm{C}_{3^{-}}$$\mathrm{PG},{ }^{13} \mathrm{C}_{3}$-G, and $\mathrm{D}_{7}$-nicotine showed a purity of $99.2 \%$, $100 \%$, and $99.7 \%$, respectively. The subjects stayed in the clinic for $84 \mathrm{~h}$ (evening of day-1 until morning of Day 4). Vaping or smoking took place only on day 1 during 10 sessions, each comprising the consumption of 10 controlled puffs (two puffs per minute, $4 \mathrm{~s}$ puff duration) by the 20 vapers or one cigarette by the 5 smokers. Before and after each sampling in the clinical study, the tanks were weighed to determine the amount of e-liquid consumed per session. The amount of e-liquid consumed was used to normalize the results. All urine voids were collected from the morning of Day 1 prior to the first vaping/smoking session until the morning of day 4 .

\section{Chemicals, standards and stock solution}

Acetaldehyde-dinitrophenylhydrazone (DNPH) (99.9\% purity), acetone-DNPH (99.7\%) acrolein-DNPH (99.8\%), formaldehyde-DNPH (99.9\%), crotonaldehyde-DNPH $(99.6 \%)$, methacrolein-DNPH $(96.7 \%)$ and propionaldehyde-DNPH (98.3\%) were purchased from Neochema (Bodenheim, Germany). 3,5,6- $\mathrm{D}_{3}$-Acetaldehyde-DNPH

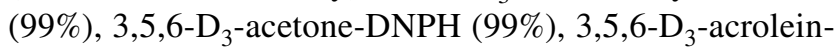
DNPH (99\%), 3,5,6-D 3 -formaldehyde-DNPH (98.8\%),

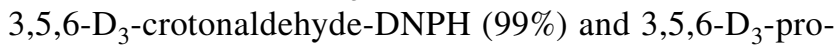
pionaldehyde-DNPH (98.6\%) were obtained from CDN Isotopes Inc. (Quebec, Canada). 2,4-Dinitrophenylhydrazine for HPLC derivatization (>99\%), perchloric acid (70\%) and pyridine (anhydrous, 99.8\%) were purchased from Sigma (Taufkirchen, Germany). Acetonitrile (ULC/MS grade) was obtained from Biosolve BV (Valkenswaad, Netherlands). Ultrapure water was prepared using the arium ${ }^{\circledR}$ pro ultrapure water system (Sartorius, Göttingen, Germany).

\section{Analysis of carbonyls in aerosol and smoke}

The carbonyls (formaldehyde, acetaldehyde, acrolein, acetone, crotonaldehyde, methacrolein, propionaldehyde) are highly volatile and reactive and therefore they were derivatized with 2,4-dinitrophenylhydrazine upon trapping, followed by dilution. 10 puffs of the EC or a single cigarette (approx. 7-8 puffs) were drawn through two glass impingers in sequence each containing $20 \mathrm{~mL}$ of an acidic dinitrophenylhydrazine derivatization solution ( $2.5 \mathrm{mM}$ in acetonitrile) according to Miller et al. (2010). The puffing regime was set according to CORESTA recommended method CRM no. 81 (CORESTA 2015) with minor modifications: puff duration: $4 \mathrm{~s}$ (instead of $3 \mathrm{~s}$ according to CRM no. 81), puff interval: $30 \mathrm{~s}$, puff volume: $55 \mathrm{~mL}$. Immediately after the trapping procedure, $200 \mu \mathrm{L}$ pyridine was added to stop the derivatization reaction. The trapping solution was diluted 1:10 (1:100 for the cigarette) with acetonitrile. Prior to the UPLC-MS/MS analysis, $10 \mu \mathrm{L}$ of the internal standard mix of the carbonyl-DNPHs was added to $100 \mu \mathrm{L}$ of the diluted sample, $5 \mu \mathrm{L}$ of which was injected for analysis.

Liquid chromatography was performed with a Shimadzu Nexera X2 UPLC system consisting of a binary pump, an 
auto-sampler, a degaser, and a column oven (Shimadzu Corp., Kyoto, Japan). A triple quadrupole mass spectrometer QTRAP ${ }^{\circledR} 6500$ + equipped with a Turbo $\mathrm{V}$ ion spray source, operating in negative ESI mode, was used for detection (AB Sciex, Darmstadt,Germany). High purity nitrogen was produced by a nitrogen generator NGM 22-LC/ MS (cmc Instruments, Eschborn, Germany). Chromatographic separation was achieved on a Kinetex ${ }^{\circledR} 5 \mu \mathrm{m}$ EVO C18 column $(150 \times 2.1 \mathrm{~mm}, 5 \mu \mathrm{m}$, Phenomenex, Aschaffenburg, Germany) with water (eluent A) and acetonitrile (eluent B) applying the following gradient: 0-5.0 min: 35-55\% B; $5.0-7.0$ min: $70 \%$ B; $7.0-7.1 \mathrm{~min}: 70-35 \%$ B; $7.1-10.0 \mathrm{~min}: 35 \% \mathrm{~B}$. The column was kept at $50{ }^{\circ} \mathrm{C}$ with a flow rate of $0.7 \mathrm{~mL} / \mathrm{min}$. Labeled and unlabeled analytes as well as their corresponding internal standards were monitored in the multiple reaction monitoring mode (MRM, Supplementary Information Table S1).

All determinations of the carbonyls were repeated eight times for EC aerosol at low $(10 \mathrm{~W})$ and high $(18 \mathrm{~W})$ wattage and ten times for cigarette mainstream smoke, respectively. The presented data were corrected for isotope overlap according to Scherer et al. (2010). The lower limit of quantification (LLOQ) was $0.2 \mathrm{ng} / \mathrm{puff}$ for EC aerosol and $0.25 \mathrm{ng} / \mathrm{puff}$ for cigarette mainstream smoke. The upper limit of quantification (ULOQ) was $100 \mathrm{ng} /$ puff for EC aerosol and $125 \mathrm{ng} /$ puff for cigarette mainstream smoke.

\section{Analysis of epoxides in aerosol and mainstream smoke}

Various trapping agents and chromatographic conditions were tested for the determination of the epoxides propylene oxide (PO) and glycidol (GLY) in EC aerosol and mainstream smoke. The analytical method showing the best performance with regard to the sensitivity and recovery is presented in the Supplementary Information. However, the sensitivity of the final method with an LLOQ of $0.05 \mu \mathrm{g} / \mathrm{mL}$ was still not sufficient for the quantification of PO and GLY in EC aerosols or smoke in our study.

\section{Analysis of the biomarkers for formaldehyde and acetaldehyde}

The specific biomarkers TCA and TCG for FA as well as MTCA and MTCG for AA were determined according to the fully validated method published by Landmesser et al. (2020). Briefly, the biomarkers were cleaned up from major matrix components by solid-phase extraction followed by derivatization under alkaline conditions using propyl chloroformate. The LC-MS/MS analysis was performed using a Shimadzu Nexera X2 UPLC system consisting of a binary pump, an autosampler, a degaser and a column oven (Shimadzu Corp., Kyoto, Japan) combined with a triple quadrupole mass spectrometer QTRAP® 6500 + equipped with a Turbo V ion spray source (AB Sciex, Darmstadt, Germany), operated in positive ESI (ESI+) mode. The presented data are corrected for isotope overlap according to Scherer et al. (2010). LLOQs and ULOQs were $0.5 \mathrm{ng} / \mathrm{mL}$ and $200 \mathrm{ng} / \mathrm{mL}$ for (M)TCA and $1.0 \mathrm{ng} / \mathrm{mL}$ and $400 \mathrm{ng} / \mathrm{mL}$ for (M)TCG in accordance with Landmesser et al. (2020).

\section{Analysis of mercapturic acids}

The following mercapturic acids were determined in $24 \mathrm{~h}$ urine samples according to Pluym et al. (2015) with modifications: 3-HPMA (biomarker for acrolein), HMPMA (crotonaldehyde), 2-HPMA (propylene oxide), and DHPMA (glycidol). DHPMA, which was not implemented in the initial method (Pluym et al. 2015) was included for the purpose of our study into the analytical method for 2-/3HPMA. LLOQs ( $\mathrm{ng} / \mathrm{mL}$ ) of the newly integrated analytes (DHPMA and all labeled mercapturic acids) were as follows: $\left[{ }^{13} \mathrm{C}_{4}\right]$-HMPMA: $5.0,\left[{ }^{13} \mathrm{C}_{3}\right]$-2-HPMA: 0.5 , $\left[{ }^{13} \mathrm{C}_{3}\right]$-3-HPMA: 0.5, DHPMA: 10 ; $\left[{ }^{13} \mathrm{C}_{3}\right]$-DHPMA: 0.8 . ULOQs $(\mathrm{ng} / \mathrm{mL})$ of the newly integrated analytes were as follows: $\left[{ }^{13} \mathrm{C}_{4}\right]$-HMPMA: $2,500,\left[{ }^{13} \mathrm{C}_{3}\right]$-2-HPMA: 2,000, $\left[{ }^{13} \mathrm{C}_{3}\right]$-3-HPMA: 10,000, DHPMA: 2,000; $\left[{ }^{13} \mathrm{C}_{3}\right]$-DHPMA: 2,000 . The applied mass transitions for the labeled analytes were selected according to the published fragmentation pathways of mercapturic acids (summarized in Supplementary Information Table S2).

Biomarker analysis was performed separately for urine fractions collected over $48 \mathrm{~h}$, beginning with the first fraction voided after start of the first vaping/smoking session on Day 1. The presented data are corrected for isotope overlap according to Scherer et al. (2010).

\section{Results}

\section{Carbonyl and epoxide levels in mainstream smoke of cigarettes and aerosol of ECs}

In cigarette mainstream smoke, all carbonyls expected to be formed from labeled PG and $\mathrm{G}$ according to Fig. 1 were detected (labeled FA, AA, ACR, and PA). In addition, ${ }^{13} \mathrm{C}$-labeled CR, AT, and MA were observed. Mean concentrations ranged from $6.3 \mathrm{ng} /$ puff for ${ }^{13} \mathrm{C}$-FA to $290 \mathrm{ng} / \mathrm{puff}$ for ${ }^{13} \mathrm{C}_{3}$-AT (Table 1). The corresponding unlabeled compounds were obtained at much higher amounts in smoke, mostly well above the ULOQ, and not further evaluated in this study.

The observed per puff amounts in the aerosol of the EC were lower than in the cigarette smoke by several orders of magnitude for the labeled carbonyls. The lowest difference was observed for ${ }^{13} \mathrm{C}$-FA with similar concentrations in EC 


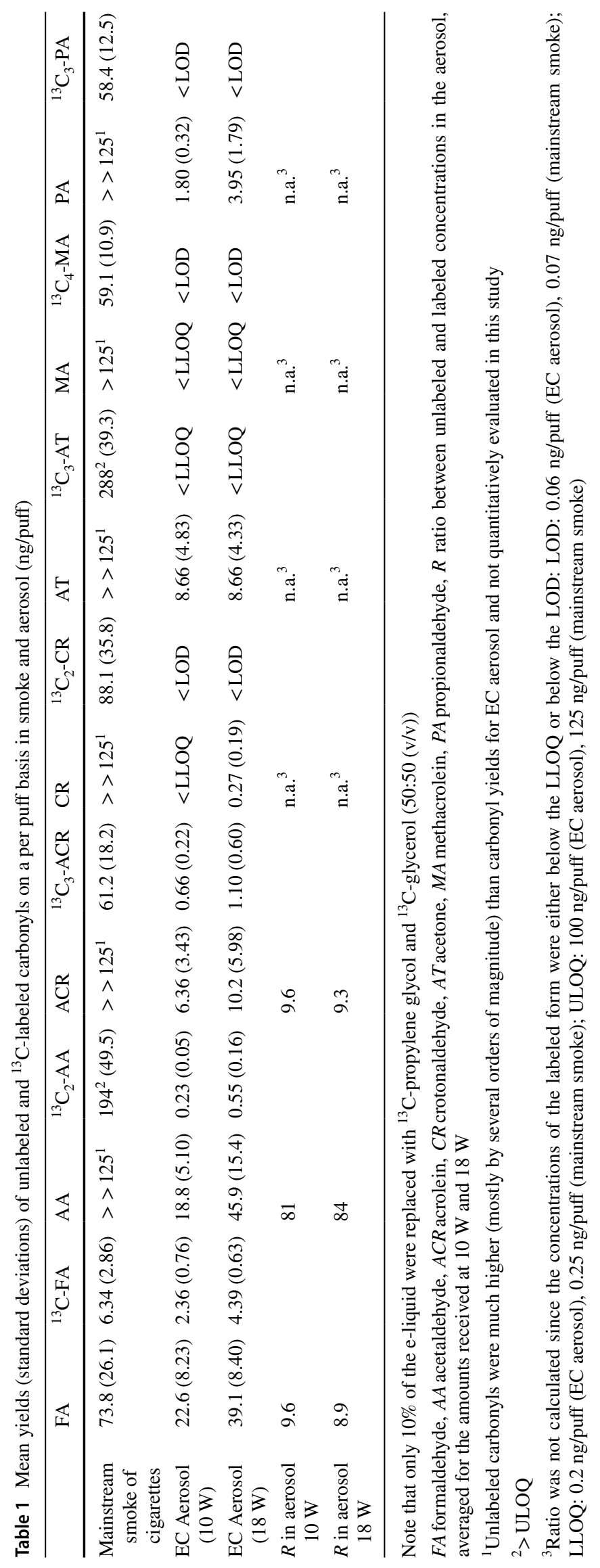


aerosol and smoke. Only ${ }^{13} \mathrm{C}$-FA, ${ }^{13} \mathrm{C}_{2}$-AA and ${ }^{13} \mathrm{C}_{3}$-ACR were quantifiable in the aerosol, averaging 2.36 and $4.39 \mathrm{ng} /$ puff, 0.23 and $0.55 \mathrm{ng} / \mathrm{puff}$ and 0.66 and $1.10 \mathrm{ng} /$ puff for the $10 \mathrm{~W}$ and $18 \mathrm{~W}$ vaping conditions, respectively. Notably, the increase of these carbonyls in the $18 \mathrm{~W}$ compared to the $10 \mathrm{~W}$ vaping conditions was around 1.6 - to 2.3 -fold resembling the increase in the wattage of 1.8 -fold. ${ }^{13} \mathrm{C}$-labeled CR, $\mathrm{MA}$ and PA were not detectable (below the limit of detection (LOD)) and ${ }^{13} \mathrm{C}_{3}$-AT was below the LLOQ in EC aerosol. In analogy to the labeled carbonyls, vaping at $10 \mathrm{~W}$ yielded lower amounts than at $18 \mathrm{~W}$ for the unlabeled analytes. The following rank order was observed for unlabeled carbonyls: methacrolein $(<$ LLOQ) $<$ crotonaldehyde ( $<$ LLOQ at $10 \mathrm{~W}$ and $0.27 \mathrm{ng} /$ puff at $18 \mathrm{~W})<$ propionaldehyde $<$ acetone $\approx$ acrolein $<$ formaldehyde $\approx$ acetaldehyde (see Table 1 ).

A ratio $(\mathrm{R}=$ amount unlabeled/amount labeled $)$ of around 10 was observed for FA and ACR in aerosol reflecting the $10 \%$ replacement of $P G$ and $G$ in the e-liquid by labeled PG and $\mathrm{G}$, while AA yielded a significantly higher ratio of 81-84 (Table 1).

The concentrations of labeled FA, AA, and ACR were expressed as ng/g e-liquid consumed. This normalization takes into account the variability in aerosol generation due to the differing wattage applied. Thus, yields per gram e-liquid consumed should be better suited to compare aerosol amounts EC between studies regardless of the puffing regime applied (Farsalinos and Gillman 2017). There were no significant differences in the yields based on e-liquid consumption between the two power settings with highest concentrations found for labeled FA (150 and $162 \mathrm{ng} / \mathrm{g}$ e-liquid) followed by labeled ACR ( 80 and $80 \mathrm{ng} / \mathrm{g}$ e-liquid) and AA (15 and $20 \mathrm{ng} / \mathrm{g}$ e-liquid).

\section{Quantification of labeled and unlabeled biomarkers in urine of smokers and vapers}

The amounts of labeled and unlabeled biomarkers excreted over $48 \mathrm{~h}$ after controlled vaping or smoking are summarized in Table 2. While ${ }^{13} \mathrm{C}_{3}$-2-HPMA (formed from inhaled ${ }^{13} \mathrm{C}_{3}$-PO) was only found in smokers, ${ }^{13} \mathrm{C}_{3}-3$-HPMA $\left({ }^{13} \mathrm{C}_{3}\right.$ ACR $),{ }^{13} \mathrm{C}_{3}$-DHPMA $\left({ }^{13} \mathrm{C}_{3}\right.$-GLY) and ${ }^{13} \mathrm{C}-\mathrm{TCA} /{ }^{13} \mathrm{C}$-TCG $\left({ }^{13} \mathrm{C}\right.$-FA) were observed in quantifiable amounts both for smokers and vapers (Fig. 3). The mercapturic acids ${ }^{13} \mathrm{C}_{2 / 4^{-}}$ HMPMA $\left({ }^{13} \mathrm{C}_{2 / 4}\right.$-CR $)$ and ${ }^{13} \mathrm{C}_{2}$-MTCA $/{ }^{13} \mathrm{C}_{2}$-MTCG $\left({ }^{13} \mathrm{C}_{2^{-}}\right.$ $\mathrm{AA})$ were not detected, neither in smokers nor in $\mathrm{EC}$ vapers.

For labeled 3-HPMA and 2-HPMA, smokers excreted at least 2-3 orders of magnitude higher amounts than the EC vapers. This difference was less pronounced (only 3-20fold) in the case of labeled DHPMA and TCA/TCG, respectively (Fig. 3). Labeled 3-HPMA, DHPMA, TCA, and TCG were obtained at similar concentrations for the two vaping conditions (10 and $18 \mathrm{~W}$ ).

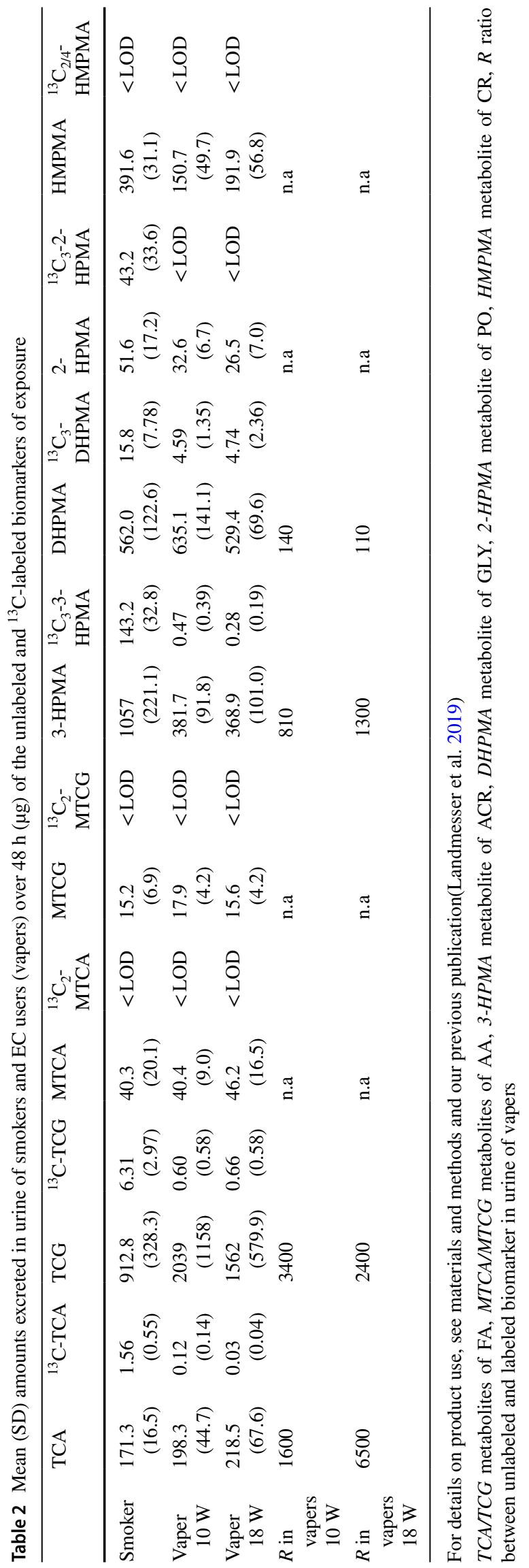



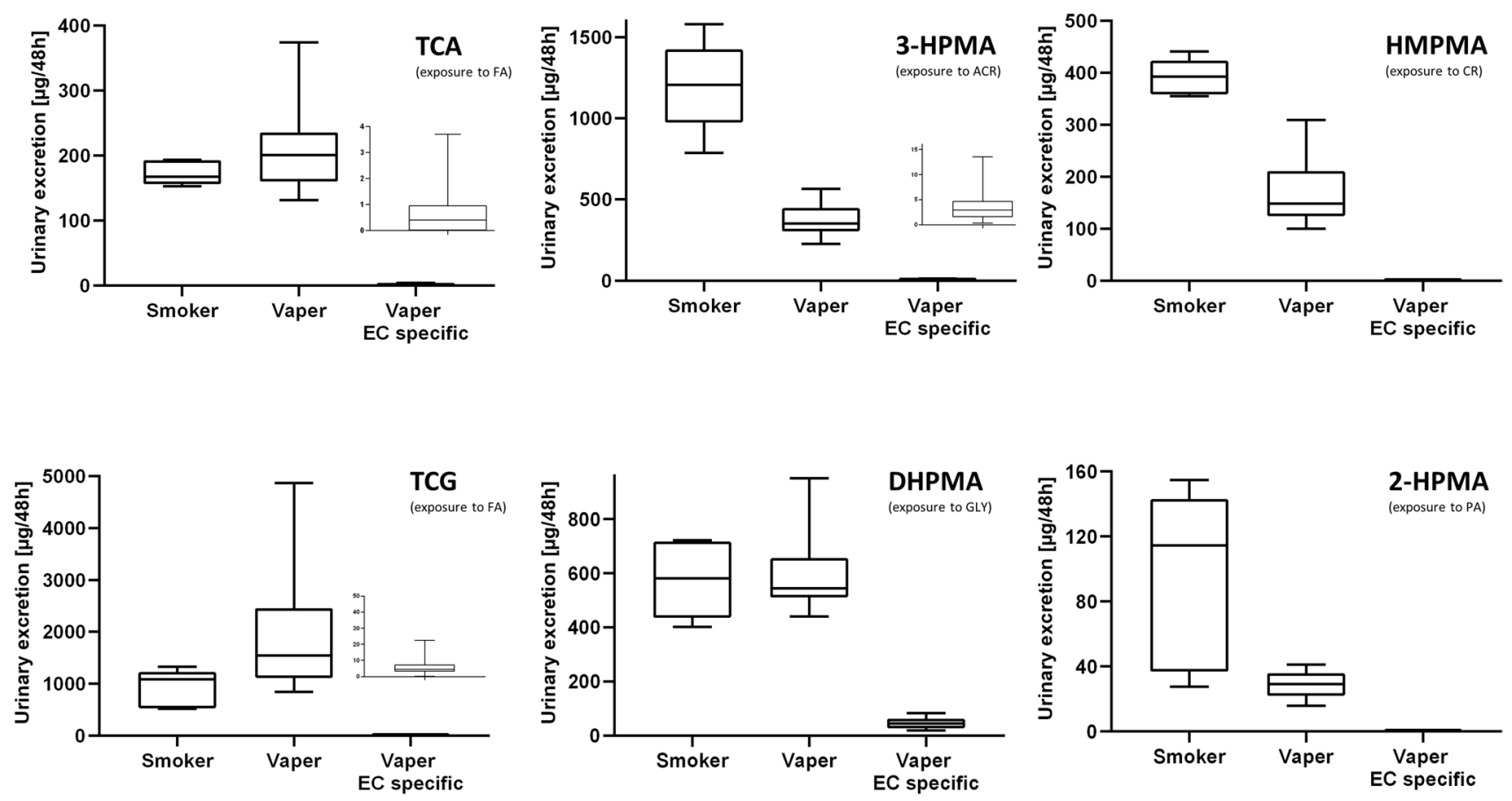

Fig. 3 Box plots of the total amounts of the biomarkers excreted over $48 \mathrm{~h}$ after controlled vaping/smoking. Total amounts were calculated as the sum of labeled and unlabeled for smokers (left box plot) and vapers (middle box plot). The EC-specific exposure corresponds to the excreted amount of labeled biomarker multiplied by 10 to account for the $10 \%$ replacement (right box plot: Vaper EC-specific). The inserted figures in the graphs for TCA, TCG and 3-HPMA show the

In terms of the unlabeled compounds, all biomarkers of interest were measurable in each subject. The ratios between unlabeled and labeled biomarkers in vapers ranged from 110 to 6500 (Table 2). The vaping-specific excretion of the biomarkers was calculated by multiplying the amount of labeled biomarker with the factor 10 (considering the $10 \%$ replacement with labeled PG and $\mathrm{G}$ in the e-liquid). These amounts are illustrated in Fig. 3 (Vaper EC specific).

The unlabeled biomarkers 3-HPMA, 2-HPMA, and HMPMA tended to be higher in smokers, whereas TCA, TCG, MTCA, MTCG and DHPMA showed similar levels in smokers and vapers (Table 2).

\section{Discussion}

Our data unequivocally confirm the formation of FA, AA, and ACR from the precursors PG and $\mathrm{G}$ in e-liquid during vaping, which is in line with previous studies (Farsalinos et al. 2015a; Geiss et al. 2015; Goniewicz et al. 2014; Sleiman et al. 2016). Geiss et al. who used a second-generation atomizer device similar to the EC used in our study, found comparable levels of FA, AA, and ACR (Geiss et al. 2015), while most studies reported higher aldehyde concentrations box plots for the vaping-specific excretion with y-axis magnified by 100 -fold for better illustration. Lines and boxes represent the median and the 25th/75th percentile, respectively. Error bars illustrate the 5th and 95th percentile. TCA/TCG biomarkers of formaldehyde, DHPMA biomarker of glycidol, 3-HPMA biomarker of acrolein, 2-HPMA biomarker of propylene oxide, HMPMA biomarker of crotonaldehyde

which may result from the different device characteristics and varying puffing regimes used throughout the studies as discussed in detail by Farsalinos et al. (2017). Interestingly, the higher carbonyl concentrations per puff at $18 \mathrm{~W}$ are clearly related to increased aerosol generation as can be deduced from the fact that the amounts of carbonyls per mass consumed e-liquid were found to be identical for both wattages. This observation indicates that, at least under the vaping conditions we applied, increasing the power from 10 to $18 \mathrm{~W}$ elevated the amount of aerosol produced but not the percentage of $P G$ and $G$ which is converted to carbonyls.

The introduction of labeled PG and G allowed us to assess the formation of carbonyls specifically formed from these e-liquid constituents. The ratio of the unlabeled to the ${ }^{13} \mathrm{C}$-labeled PG and $\mathrm{G}$ in the e-liquid of 10:1 was well reflected in the EC aerosol for FA and ACR (Table 1), indicating that both aldehydes are mainly (or almost exclusively) formed from $\mathrm{PG}$ and $\mathrm{G}$ during vaping. In contrast, for AA a ratio of around 80 was observed, while $C R$, AT and PA were only detected in their unlabeled form. This suggests that other sources than PG and G contribute to a major extent to the formation of AA. Sugars and flavors were recently discussed as possible sources for carbonyl emissions in EC aerosols (Fagan et al. 2018; Khlystov and Samburova 2016). 
The use of stable isotope-labeled flavoring ingredients and sugars could be a useful strategy in future studies to further evaluate their chemical fate with regard to vaping.

All seven ${ }^{13} \mathrm{C}$-labeled aldehydes investigated in our study were found in cigarette mainstream smoke indicating that the formation of AA, CR, AT, and PA from PG and G is possible, albeit at higher temperatures than achievable under common vaping conditions (up to $350^{\circ} \mathrm{C}$ ) (Geiss et al. 2016). Apparently, AA, AT and PA (C2 and $\mathrm{C} 3$ compounds) are formed due to decomposition of PG and G (Uchiyama et al. 2020). CR (4 carbon atoms) is more likely to be formed after decomposition of $\mathrm{PG}$ and $\mathrm{G}$ from $\mathrm{AA}$ by aldol condensation (Fig. 1) implying the need for harsher conditions-in this case higher temperatures (Luo and Falconer 1999).

Labeled biomarker analysis in urine allowed us to link the machine-derived aerosol data with actual human exposure values. The difference in smoke and vapor yields was clearly reflected in the biomarker levels for FA and ACR since the respective labeled biomarkers ${ }^{13} \mathrm{C}$-TCA, ${ }^{13} \mathrm{C}$-TCG and ${ }^{13} \mathrm{C}_{3}$-3-HPMA were detected at much higher levels in smokers (Fig. 3). Hence, our approach using stable isotope-labeled precursors was capable of detecting exposure to FA and ACR specifically from vaping at a daily intake of approx. 1.1 to $2.2 \mu \mathrm{g}$ based on the aerosol data and the average e-liquid consumption of $1.2 \mathrm{~g}$ per day (Landmesser et al. 2019). Unfortunately, the labeled biomarkers of AA exposure, MTCA and MTCG, respectively, could not be determined due to insufficient long-term stability in urine of only 2 months (Landmesser et al. 2020). Thus, MTCA and MTCG are not suited to assess AA exposure from smoking and vaping.

Furthermore, it was assumed that PG and G may also serve as precursors for the epoxides PO and GLY (Uchiyama et al. 2020). For methodological problems, the expected (labeled) epoxides could not be determined, neither in mainstream smoke of conventional cigarettes nor in aerosol of ECs. Analysis of the corresponding labeled biomarkers in urine revealed exposure to PO (2-HPMA) exclusively in smokers while glycidol exposure (DHPMA) was detected both in the case of smoking and vaping, at approx. threefold lower amounts in the EC vapers (Table 2). Thus, PO seemed to be formed from the precursors PG and G under pyrolytic (smoking) conditions only, while GLY was observed at appreciable amounts already under vaping conditions as can be concluded from the biomarker analysis. Moreover, there was no difference in biomarker levels between subjects using the $\mathrm{EC}$ at 10 and $18 \mathrm{~W}$ despite the higher per puff carbonyl yields in the aerosol at $18 \mathrm{~W}$. In contrast, excretion rates of PG in urine over $48 \mathrm{~h}$ correlated with the increased wattage (Landmesser et al. 2019). Presumably, the generally low exposure to carbonyls in our study was not sufficient to discriminate the vaper subgroups in terms of biomarker excretion rates. These findings emphasize the importance of biomarker analysis in addition to machine-derived aerosol data for a comprehensive exposure and risk assessment.

This study demonstrates the potential utility of the stable isotope labeling approach by comparing biomarker data for unlabeled and labeled compounds from cigarette smoke and EC aerosols. For the unlabeled biomarkers, differences between smokers and vapers were marginal (if any) for TCA/TCG (exposure to FA) and DHPMA (GLY). A more pronounced difference for the unlabeled biomarkers was obtained in the case of PO (2-HPMA), ACR (3-HPMA), and CR (HMPMA) since smoking of combustible cigarettes is a major source as reported in previous studies (Alwis et al. 2012, 2015; Pluym et al. 2015).

The difference in the ratio between the unlabeled and labeled biomarkers of exposure was much more pronounced ( $R=110-6500)$ compared with the ratios found for aerosol (9-84) (Table 2). Moreover, the estimated EC-specific uptake in vapers (box plot termed "Vaper EC specific" in Fig. 3) compared to the overall exposure in vapers and smokers (box plots termed "Vaper" and "Smoker" in Fig. 3) demonstrated that EC use only accounted for approximately $0.4 \%, 1.0 \%$, and $8 \%$ of the overall exposure to formaldehyde (TCA/TCG), acrolein (3-HPMA) and glycidol (DHPMA) in vapers (see Supplementary Information for details about the calculation) while no EC specific uptake of PO (2-HPMA) and CR (HMPMA) was observed. This indicates other sources than vaping, like diet and endogenous formation, contribute primarily to the observed biomarker levels of TCA/TCG, 3-HPMA and DHPMA in exclusive vapers (Cederbaum 2012; Cloos et al. 2008; de Groot et al. 2009; Dhareshwar and Stella 2008; Eckert et al. 2011; Hou and Yu 2010; O'Sullivan et al. 2004). For example, vegetable oils and fats were recently identified as a major source of glycidol exposure (Abraham et al. 2019).

The results of this study should be considered in the context of the limitations with respect to the investigated specimen and the sample size in this study. In addition to the aerosol analysis and urinary excretion discussed here, local effects in terms of toxicant exposure may not be neglected as for example nicotine was identified as a source of NNN exposure in the oral cavity of EC vapers (Bustamante et al. 2018). Local exposure, e.g., in the oral cavity was beyond the scope of our study. However, possible local effects should be addressed in future studies for a more profound risk assessment in terms of EC use. Regarding the sample size, 20 male vapers were included limiting the generalizability of the results. Moreover, thermal degradation of PG and $\mathrm{G}$ depends on the applied power settings and properties of the device (Gillman et al. 2016). Hence, larger studies including both sexes and users of different EC devices are needed to substantiate our findings. Nevertheless, our study clearly demonstrates the advantage of the stable isotope labelling approach to decipher the EC use specific exposure 
to toxicants which may be formed from the main constituents PG and G.

\section{Conclusions}

We were able to determine the exposure to various carbonyls and epoxides, resulting from thermal degradation of propylene glycol and glycerol under smoking and vaping conditions using a stable isotope labeling approach. The formation of several toxicants such as crotonaldehyde, methacrolein and acetone were only observed during combustion of conventional cigarettes while propylene glycol and glycerol can also be decomposed to formaldehyde, acetaldehyde, acrolein and glycidol under common vaping conditions, overall at a much lower degree compared to smoking. Assessment of the corresponding biomarkers of exposure in urine confirmed the findings from aerosol data for formaldehyde and acrolein, while a suitable biomarker for acetaldehyde exposure still needs to be identified. This is the first study to prove the EC-specific uptake of glycidol due to the degradation of propylene glycol and/or glycerol during vaping. However, vaping appears to be a minor source with respect to the general exposure to formaldehyde, acrolein and glycidol.

Supplementary Information The online version contains supplementary material available at https://doi.org/10.1007/s00204-021-03097-x.

Acknowledgements The authors would like to thank 'Happy Liquid' Ltd, Munich, Germany for providing the unlabeled e-liquids used in this study.

Author contributions AL: investigation, formal analysis, writingoriginal draft. MS: supervision, writing-review and editing. GS: conceptualization, writing - review and editing. MS: writing-review and editing. JSE: writing - review and editing. RN: writing-review and editing. NP: supervision, formal analysis, writing — original draft.

Funding This research was supported by Altria Client Services LLC, 601 East Jackson Street, Richmond, VA 23219, USA.

\section{Availability of data and material Not applicable.}

Code availability Not applicable.

\section{Declarations}

Conflict of interest The authors Gerhard Scherer, Max Scherer, Nikola Pluym and Anne Landmesser work for ABF GmbH in Planegg, Germany, an independent contract research laboratory and declare no conflicts of interest regarding the publication of this paper. The authors Mohamadi Sakar and Jeff Edmiston are employed by Altria Client Services LLC.

Ethical approval Ethical approval was received according to the Helsinki declaration by the Ethical Commission of the Medical Chamber of Hamburg (Germany) and informed consent was signed by all study participants.
Open Access This article is licensed under a Creative Commons Attribution 4.0 International License, which permits use, sharing, adaptation, distribution and reproduction in any medium or format, as long as you give appropriate credit to the original author(s) and the source, provide a link to the Creative Commons licence, and indicate if changes were made. The images or other third party material in this article are included in the article's Creative Commons licence, unless indicated otherwise in a credit line to the material. If material is not included in the article's Creative Commons licence and your intended use is not permitted by statutory regulation or exceeds the permitted use, you will need to obtain permission directly from the copyright holder. To view a copy of this licence, visit http://creativecommons.org/licenses/by/4.0/.

\section{References}

Abraham K, Hielscher J, Kaufholz T, Mielke H, Lampen A, Monien B (2019) The hemoglobin adduct $N$-(2,3-dihydroxypropyl)-valine as biomarker of dietary exposure to glycidyl esters: a controlled exposure study in humans. Arch Toxicol 93(2):331-340. https:// doi.org/10.1007/s00204-018-2373-y

Alwis KU, Blount BC, Britt AS, Patel D, Ashley DL (2012) Simultaneous analysis of 28 urinary VOC metabolites using ultra high performance liquid chromatography coupled with electrospray ionization tandem mass spectrometry (UPLC-ESI/MSMS). Anal Chim Acta 750:152-160

Alwis KU, deCastro BR, Morrow JC, Blount BC (2015) Acrolein exposure in US tobacco smokers and non-tobacco users: NHANES 2005-2006. Environ Health Perspect 123:1302-1308

Bakhiya N, Abraham K, Gürtler R, Appel KE, Lampen A (2011) Toxicological assessment of 3-chloropropane-1,2-diol and glycidol fatty acid esters in food. Mol Nutr Food Res 55(4):509-521. https://doi.org/10.1002/mnfr.201000550

Beard E, West R, Michie S, Brown J (2020) Association of prevalence of electronic cigarette use with smoking cessation and cigarette consumption in England: a time-series analysis between 2006 and 2017. Addiction 115(5):961-974. https://doi.org/10.1111/ add. 14851

Bequette BJ, Sunny NE, El-Kadi SW, Owens SL (2006) Application of stable isotopes and mass isotopomer distribution analysis to the study of intermediary metabolism of nutrients. J Anim Sci 84(Suppl):E50-E59

Bustamante G, Ma B, Yakovlev G et al (2018) Presence of the carcinogen $N$ '-nitrosonornicotine in saliva of e-cigarette users. Chem Res Toxicol 31(8):731-738. https://doi.org/10.1021/acs.chemrestox. 8 b00089

Cederbaum AI (2012) Alcohol metabolism. Clin Liver Dis 16(4):667685. https://doi.org/10.1016/j.cld.2012.08.002

Cloos PA, Christensen J, Agger K, Helin K (2008) Erasing the methyl mark: histone demethylases at the center of cellular differentiation and disease. Genes Dev 22(9):1115-1140. https://doi.org/10. $1101 /$ gad. 1652908

CORESTA (2015) Recommended Method No. 81: routine analytical machine for e-cigarette aerosol generation and collection-definitions and standard conditions

Cullen KA, Gentzke AS, Sawdey MD et al (2019) e-cigarette use among youth in the United States, 2019. JAMA. https://doi.org/ 10.1001/jama.2019.18387

Dai H, Leventhal AM (2019) Prevalence of e-cigarette use among adults in the United States, 2014-2018. JAMA 322(18):18241827. https://doi.org/10.1001/jama.2019.15331

Darmaun D, Mauras N (2005) Use of stable isotopes to assess protein and amino acid metabolism in children and adolescents: a brief review. Horm Res 64(Suppl 3):32-37. https://doi.org/10.1159/ 000089315 
de Groot AC, Flyvholm MA, Lensen G, Menné T, Coenraads PJ (2009) Formaldehyde-releasers: relationship to formaldehyde contact allergy. Contact allergy to formaldehyde and inventory of formaldehyde-releasers. Contact Dermat 61(2):63-85. https:// doi.org/10.1111/j.1600-0536.2009.01582.x

Dhareshwar SS, Stella VJ (2008) Your prodrug releases formaldehyde: should you be concerned? No! J Pharm Sci 97(10):4184-4193. https://doi.org/10.1002/jps.21319

Diekmann J, Douda M, Rustemeier K (2006) Rapid and sensitive method for the determination of propylene oxide in cigarette mainstream smoke by gas chromatography-mass spectrometry. JChromatogrSci 44(1):32-34

Eckert E, Schmid K, Schaller B, Hiddemann-Koca K, Drexler H, Göen T (2011) Mercapturic acids as metabolites of alkylating substances in urine samples of German inhabitants. Int J Hyg Environ Health 214(3):196-204. https://doi.org/10.1016/j.ijheh. 2011.03.001

Evershed RP, Crossman ZM, Bull ID et al (2006) 13C-Labelling of lipids to investigate microbial communities in the environment. Curr Opin Biotechnol 17(1):72-82. https://doi.org/10.1016/j.copbio.2006.01.003

Fagan P, Pokhrel P, Herzog TA et al (2018) Sugar and aldehyde content in flavored electronic cigarette liquids. Nicotine Tob Res 20(8):985-992. https://doi.org/10.1093/ntr/ntx234

Farsalinos KE, Gillman G (2017) Carbonyl emissions in e-cigarette aerosol: a systematic review and methodological considerations. Front Physiol 8:1119. https://doi.org/10.3389/fphys.2017.01119

Farsalinos KE, Kistler KA, Gillman G, Voudris V (2015a) Evaluation of electronic cigarette liquids and aerosol for the presence of selected inhalation toxins. Nicotine Tob Res 17(2):168-174. https://doi.org/10.1093/ntr/ntu176

Farsalinos KE, Voudris V, Poulas K (2015b) E-cigarettes generate high levels of aldehydes only in "dry puff" conditions. Addiction 110(8):1352-1356. https://doi.org/10.1111/add.12942

Feron VJ, Til HP, de Vrijer F, Woutersen RA, Cassee FR, van Bladeren PJ (1991) Aldehydes: occurrence, carcinogenic potential, mechanism of action and risk assessment. Mutat Res 259(3-4):363-385. https://doi.org/10.1016/0165-1218(91)90128-9

Flora JW, Meruva N, Huang CB et al (2016) Characterization of potential impurities and degradation products in electronic cigarette formulations and aerosols. Regul Toxicol Pharmacol 74:1-11

Geiss O, Bianchi I, Barahona F, Barrero-Moreno J (2015) Characterisation of mainstream and passive vapours emitted by selected electronic cigarettes. Int J Hyg Environ Health 218(1):169-180. https://doi.org/10.1016/j.ijheh.2014.10.001 (Epub 2014 Oct 13)

Geiss O, Bianchi I, Barrero-Moreno J (2016) Correlation of volatile carbonyl yields emitted by e-cigarettes with the temperature of the heating coil and the perceived sensorial quality of the generated vapours. Int J Hyg Environ Health. https://doi.org/10.1016/j. ijheh.2016.01.004

Gillman IG, Kistler KA, Stewart EW, Paolantonio AR (2016) Effect of variable power levels on the yield of total aerosol mass and formation of aldehydes in e-cigarette aerosols. Regul Toxicol Pharmacol RTP 75:58-65. https://doi.org/10.1016/j.yrtph.2015.12.019

Goniewicz ML, Knysak J, Gawron M et al (2014) Levels of selected carcinogens and toxicants in vapour from electronic cigarettes. Tob Control 23(2):133-139. https://doi.org/10.1136/tobaccocon trol-2012-050859

Hou H, Yu H (2010) Structural insights into histone lysine demethylation. Curr Opin Struct Biol 20(6):739-748. https://doi.org/10. 1016/j.sbi.2010.09.006

Hutzler C, Paschke M, Kruschinski S, Henkler F, Hahn J, Luch A (2014) Chemical hazards present in liquids and vapors of electronic cigarettes. Arch Toxicol 88:1295-1308

Kapan A, Stefanac S, Sandner I, Haider S, Grabovac I, Dorner TE (2020) Use of electronic cigarettes in european populations: a narrative review. Int J Environ Res Public Health. https://doi.org/ 10.3390/ijerph17061971

Khlystov A, Samburova V (2016) Flavoring compounds dominate toxic aldehyde production during e-cigarette vaping. Environ Sci Technol 50(23):13080-13085. https://doi.org/10.1021/acs.est.6b05145

Landmesser A, Scherer M, Pluym N et al (2019) Biomarkers of exposure specific to e-vapor products based on stable-isotope labeled ingredients. Nicotine Tob Res 21(3):314-322. https://doi.org/10. 1093/ntr/nty204

Landmesser A, Scherer G, Pluym N, Niessner R, Scherer M (2020) A novel quantification method for sulfur-containing biomarkers of formaldehyde and acetaldehyde exposure in human urine and plasma samples. Anal Bioanal Chem 412(27):7535-7546. https:// doi.org/10.1007/s00216-020-02888-y

Luo S, Falconer JL (1999) Aldol condensation of acetaldehyde to form high molecular weight compounds on $\mathrm{TiO}_{2}$. Catal Lett 57(3):89_ 93. https://doi.org/10.1023/A:1019003817314

Miller JHT, Gardner WP, Gonzalez RR (2010) UHPLC separation with MS analysis for eight carbonyl compounds in mainstream tobacco smoke. J Chromatogr Sci 48(1):12-17. https://doi.org/10.1093/ chromsci/48.1.12

Moghe A, Ghare S, Lamoreau B et al (2015) Molecular mechanisms of acrolein toxicity: relevance to human disease. Toxicol Sci 143(2):242-255. https://doi.org/10.1093/toxsci/kfu233

O’Sullivan J, Unzeta M, Healy J, O'Sullivan MI, Davey G, Tipton KF (2004) Semicarbazide-sensitive amine oxidases: enzymes with quite a lot to do. Neurotoxicology 25(1-2):303-315. https://doi. org/10.1016/s0161-813x(03)00117-7

Pluym N, Gilch G, Scherer G, Scherer M (2015) Analysis of 18 urinary mercapturic acids by two high-throughput multiplex-LC-MS/MS methods. Anal Bioanal Chem 407(18):5463-5476. https://doi.org/ 10.1007/s00216-015-8719-x

Sampson MM, Chambers DM, Pazo DY, Moliere F, Blount BC, Watson CH (2014) Simultaneous analysis of 22 volatile organic compounds in cigarette smoke using gas sampling bags for highthroughput SPME. Anal Chem. https://doi.org/10.1021/ac501 5518

Scherer M, Schmitz G, Liebisch G (2010) Simultaneous quantification of cardiolipin, bis(monoacylglycero)phosphate and their precursors by hydrophilic interaction LC-MS/MS including correction of isotopic overlap. Anal Chem 82(21):8794-8799. https://doi. org/10.1021/ac1021826

Sleiman M, Logue JM, Montesinos VN et al (2016) Emissions from electronic cigarettes: key parameters affecting the release of harmful chemicals. Environ Sci Technol 50(17):9644-9651. https://doi. org/10.1021/acs.est.6b01741

Sodhi SK, Khanna A (2015) More on hidden formaldehyde in e-cigarette aerosols. N Engl J Med 372(16):1576. https://doi.org/10. 1056/NEJMc1502242\#SA3

Tayyarah R, Long GA (2014) Comparison of select analytes in aerosol from e-cigarettes with smoke from conventional cigarettes and with ambient air. Regul Toxicol Pharmacol 70(3):704-710

Uchiyama S, Noguchi M, Sato A, Ishitsuka M, Inaba Y, Kunugita N (2020) Determination of thermal decomposition products generated from e-cigarettes. Chem Res Toxicol 33(2):576-583. https:// doi.org/10.1021/acs.chemrestox.9b00410

Wittmann C (2002) Metabolic flux analysis using mass spectrometry. Adv Biochem Eng Biotechnol 74:39-64

Publisher's Note Springer Nature remains neutral with regard to jurisdictional claims in published maps and institutional affiliations. 